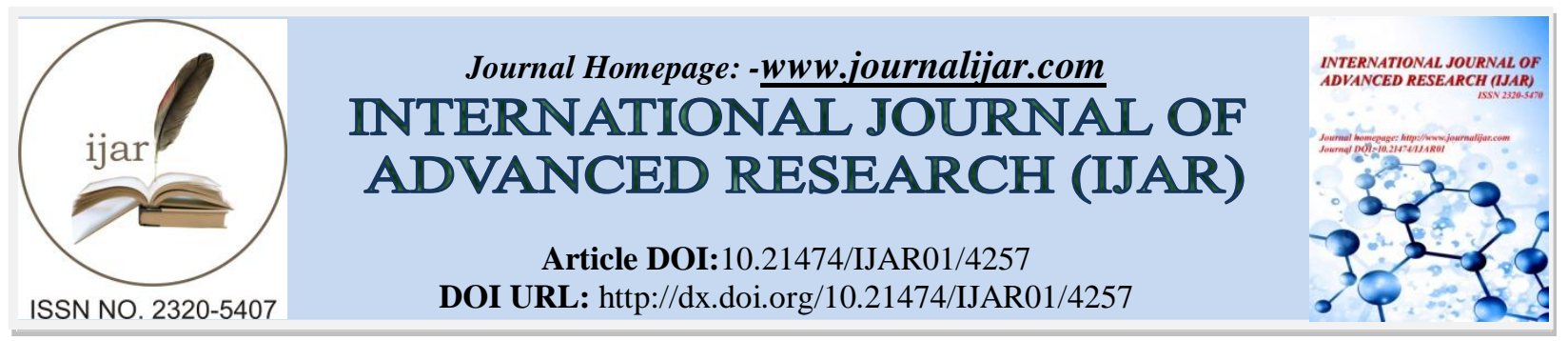

RESEARCH ARTICLE

\title{
A GREATER PRICE FOR GREEN GOODSEVIDENCE THAT GREEN MARKETING MAKES CONSUMERS PAY MORE
}

Dr. Alka Singh Bhatt.

Assistant Professor, Amity University, Lucknow

\section{Manuscript Info}

Manuscript History

Received: 26 March 2017

Final Accepted: 29 April 2017

Published: May 2017

Key words:-

Green Marketing, Environmental

Marketing, Green Consumer, Strategy.

\section{Abstract}

In today's business world environmental issues plays an important role in marketing. All most all the governments around the world have concerned about green marketing activities that they have attempted to regulate them. For example, in the United States (US) the Federal Trade Commission and the National Association of Attorneys-General have developed extensive documents examining green marketing. There has been little attempt to academically examine the impact of environmental or green marketing activities on consumers. This research aims to study whether consumers will pay more for green products or eco-friendly products. Our results will help in explaining why firms may pledge green production, green marketing and similar activities.

Copy Right, IJAR, 2017,. All rights reserved.

\section{Introduction:-}

A broad and growing set of for profit organisations are offering green products and following green marketing practices. While many factors may motivate firms to engage in this behaviour, some of these actions may be driven in part by consumer's expressed preferences for products offered by socially responsible firms. According to a 1999 survey by Cone/Roper, $67 \%$ respondents agreed that they would favour retailers/brands associated with a good cause, all else equal (Meyer, 1999). Remarkable competition is going on among the consumer, industrial and service products. Since society is becoming more anxious and concerned with the natural environment, businesses have started to adjust their behaviour in an attempt to address society's new concerns. The extent to which companies are engaging in "green" marketing is expanding rapidly; consequently consumers are being exposed to a large number of green messages. Such marketing communication mix is a composition of green products, green labeling, ways for consumers to reduce their carbon footprint, and so on.

It is an empirical question whether consumers actually will pay more for green products? How they will reciprocate to the green marketing activities? One view is that these products contain an additional favorable attribute, and this should increase demand for such products. Kotchen (2006) in his research suggests that under reasonable conditions opportunities to purchase "green" products may improve as compared to any product. An opposing view suggests that consumers doubt green claims and is turned off by the higher prices. According to Alston and Roberts, green appeals are not likely to attract mainstream consumers unless they also offer a desirable benefit, viz., cost-savings or improved product performance (Alston and Roberts, 2005) By contrast; we examine consumer behaviour in the market place. In particular, we provide evidence that consumer will not merely announce an intention to favour green claims, but is also willing to pay premium for green products. 


\section{Literature Review:-}

The environmental or green marketing is a relatively new focus in business endeavors', a strategic marketing approach that began to reach prominence in the last quarter of $20^{\text {th }}$ century (Ottman, 1998). While several companies have utilized green marketing strategies as a linchpin to business success, for instance green labels such as energy star, green seal, recyclable, renewable, the overall business success of an environmental marketing focus has been somewhat sporadic (Buchholz, 1998). Indeed, some firms may have come to regard green marketing concerns as a minor strategic focus or even as a niche approach to the market (Fuller, 1999; Peattie, 1999)

Consumer preferences for goods are affected by various combinations of environmentally-oriented and non-green components of the marketing mix. For instance, in the case of product usage convenience, an alternative fuel vehicle with reduced emissions may be preferred only if the alternative fuel is readily available. Thus, variation of individual mix attributes will impact on demand, based on how consumers value each attribute and tradeoff in relation to the overall bundle of value offered (Kimery and Rinehart 1998, Miller 1997). For example, in a 'green' versus 'non-green' framework, a product such as dishwashing liquid may be made of recycled packaging materials and non-polluting contents, or have neither characteristic. It may be priced based on principles of lifetime value to the consumer and the environment, or priced solely on a competitive low-cost basis irrespective of environmentally friendly, or this promotional aspect may be ignored in its entirety. Variation of each and all of these marketing mix components, or of the marketing mix in general, will impact on consumer decision making, resulting in tradeoffs depending on individual prioritization (Christopher and Mc Donald 1995).

In addition to marketing mix variations impacts upon consumer preferences, the level of purchase involvement may affect the perceived utility of an environmentally-marketed product (Kimery and Rinehart 1998). For instance, a higher level of consumer involvement would be expected while contemplating the purchase of an automobile as opposed to a relatively low-involvement product such as paper towels. Similarly, evaluation of marketing mix characteristics is modified by consumer perception of the level of environmental impact of the product (McIntyre, Thomas, and Gilbert 1999). If a product viz. milk is perceived as having relatively little environmental life-cycle impact from production to consumption to disposal (though milk may in fact have a relatively high environmental impact), emphasis on environmental marketing mix attributes may be of less importance while evaluating different brands of milk than may be the case with a product of higher perceived environmental impact, such as timber products (Vlosky, Ozanne, Fontenot, 1999).

A number of other factors impact on consumer evaluation of environmentally-marketed products. Demographic variables such as age, income level, education level, even place or residence have been identified as important moderators (Brown and Wahlers 1998, Ottman 1998, Piasecki et el 1997). For example, some studies have found that those with higher levels of education may tend to be more aware of current environmental issues than lessereducated individuals, which will affect the green product evaluation process (Chan and Lau 2000). Indeed, the literature suggests that consumer behaviour will vary based on the individual level of environmental knowledge as well as the level of environmental orientation or commitment (Henriques and Sadorsky 1998, Ottman 1998, Schuwerk and Lefkoff-Hagins 1995, Straughan and Roberts 1999). For instance, in the case of environmental knowledge, a consumer who is aware of the environmental impacts associated with the generation of electricity may tend to more closely evaluate the credibility of green promotional claims by energy providers than would a lessknowledgeable consumer. In the same vein, a consumer who is not environmentally oriented, who might describe themselves as 'brown' rather than 'green', may value convenience over environmental sensitivity when choosing between competitive products (Schuwerk and Lefkoff-Hagins 1995). Whilst there is some ambiguity within the research as to which of these factors, environmental knowledge or orientation, is the more decisive in terms of consumer purchase decisions, most researchers do agree that both act as moderators. Thus, it is important to consider the interaction and relative impact of each on consumer preference for environmentally marketed goods.

Much valuable work has been accomplished in each of the above discipline and considerations with regard to environmental marketing, and has led to a fuller and cleaner understanding of various aspects within the field. An example might be the identification of a particular age/income target market segment which is currently searching for more environmentally-friendly product alternatives, thus affording a potential new customer base for an enterprising business. As yet no research has been undertaken to know whether consumers will just favour the green products will actually pay premium for such products. 


\section{Objective of the Study:-}

In recent decades, the population of India comprising both consumers and producers have expressed increasing concern about the environmental impact of products. Considerable attention has been directed towards green products such as organic foods, recyclable paper, phosphate-free detergents, energy efficient lighting. Consumer attitudes to nutrition and healthy foods and sensitivity to environmental issues have also been found to be influential in India. The present study reviews the changes and attitudes of the population toward business and the environment and explores the demand and supply characteristics of green products in India. The purpose of this research is to find out the willingness of Indian consumers to pay premium for the green products.

Theoretical Framework

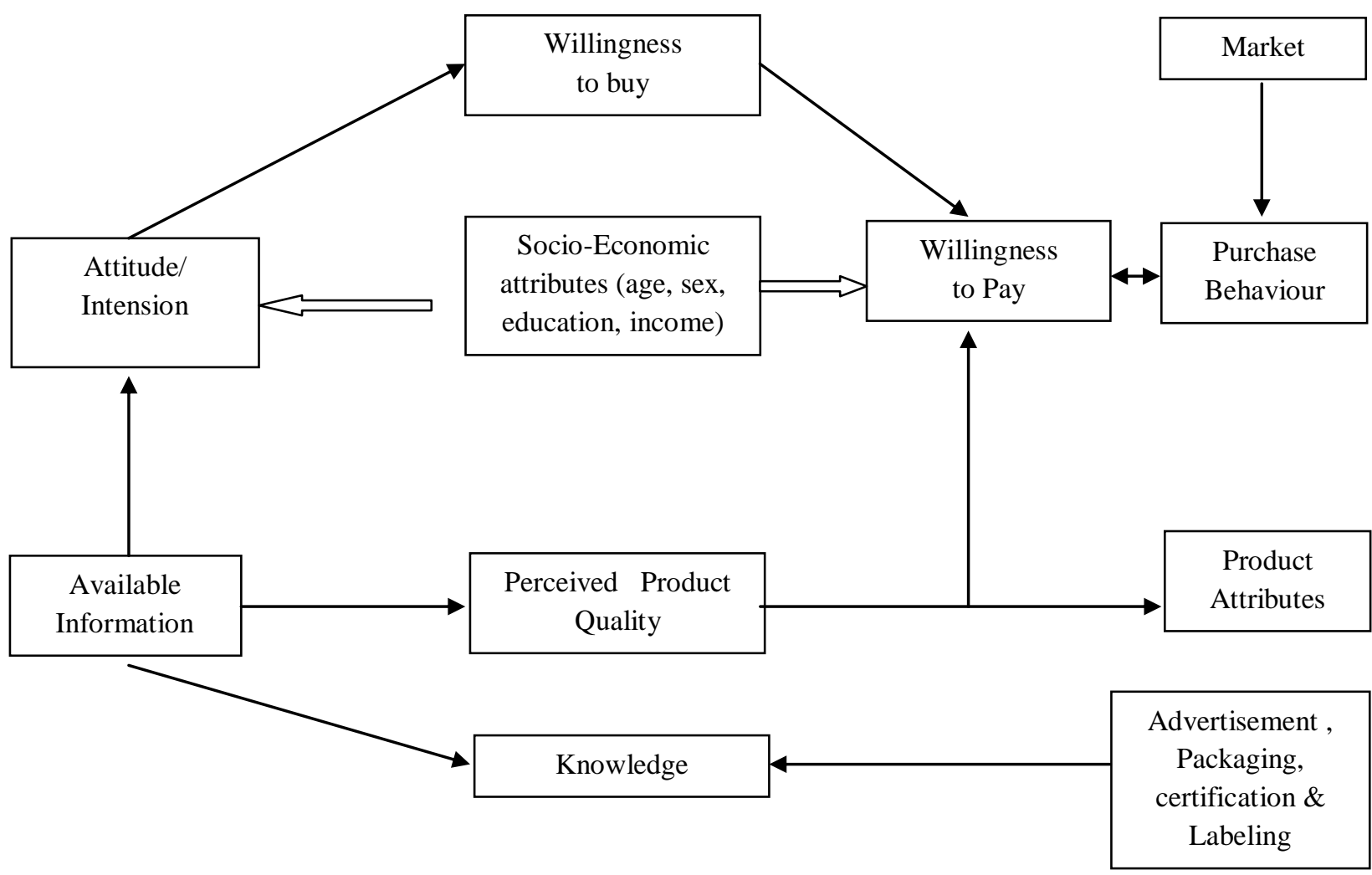

Figure 1:- Framework reflecting consumer behavior towards green products (adopted from Millock (2002) and Bonti-Ankomah and Yiridoe (2006)

In general, the willingness to pay a price premium decreases as the price premium increases, consistent with the law of demand. In consumer behavior theory, consumers make their own decisions to balance the marginal utility and marginal price of one unit of green products.

In this research, a simple framework was used (Fig.1) to analyze consumer behavior towards green products, which includes the willingness to pay a price premium. Consumers decide whether to buy a product or not based on three main aspects: Knowledge, Attitude and Intention. Knowledge about products and their benefits influences their willingness to pay for the products. Knowledge of people is affected by type and quality of information made available to consumers. Advertisement, quality packaging, labeling and certification play pivotal role in knowledge enrichment. Once a consumer is ready to buy, the next step is to see how much he or she is willing to pay for the product. Purchase behavior reflects the real WTP and the consumer gains positive or negative experiences which will reversely affect consumers' WTP in future. Knowledge and awareness have respectively direct and indirect effects on attitudes toward consumer to choose the products, and the willingness to pay a price premium, so they are 
important factors determining the demand. Thus, awareness and knowledge about green products/green claims are critical in the consumer willingness to pay more for the product.

\section{Methodology:-}

Exploratory research is taken up which involves an in-depth study and review of the existing literature. This embraces review of works on green products, green pricing, green promotion, green marketing and green placement or distribution. Further two main surveys were conducted. The purpose of the first survey was to investigate the awareness and intention of the Indian population to purchase green products, their perceptions and attitudes toward green products, green marketing claims and reasons that hinder the purchase of these products. Their willingness to pay premium for such products. The second survey was directed at the company executives/retailers and its purpose was to examine their attitudes toward green versus conventional products, and the challenges they are facing in marketing green products in India. This research provides information on green marketing practices of firms in India. It focuses on areas where companies need to concentrate and the ways they can effectively deploy a Green Marketing strategy.

\section{Findings of the Study:-}

Greenness' of Respondents:-

More than nine out of ten respondents $(90 \%)$ have incorporated some level of "greenness" into their daily lives only $10 \%$ are not "green" at all. Although most respondents have integrated "green" activity into their daily lives, few $(8.8 \%)$ are completely "green". In fact, a large percentage (43.9\%) of respondents is aspirationally "green" incorporating a "few things that are green into their daily", and another 37.3\% "attempt to be as green as possible, but not 100\%". Interestingly, men lead women for being "completely green" $-12.1 \%$ versus $5.3 \%$, respectively. (Chart 1)

\section{"Greenness" of Respondents}

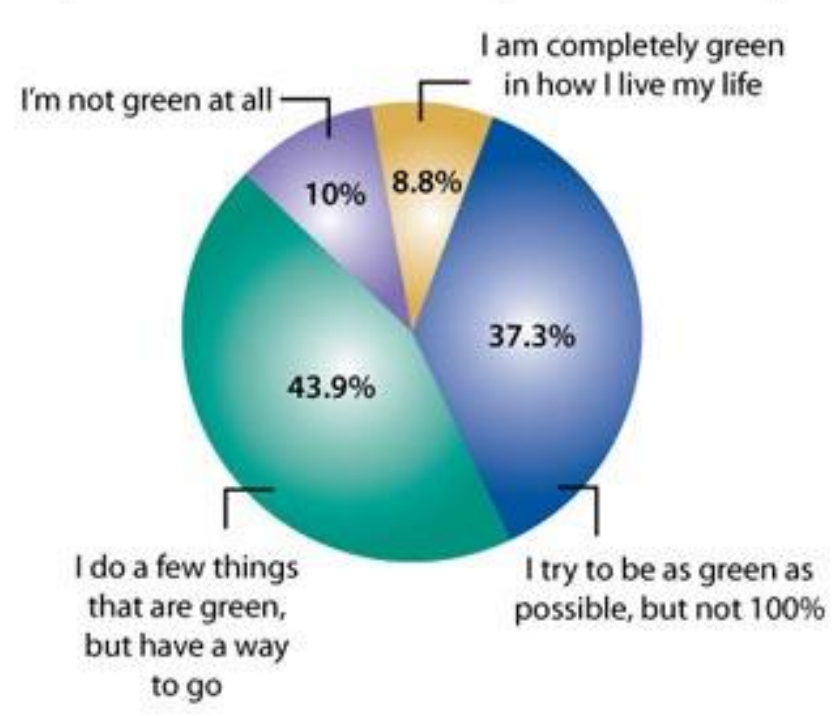

Chart 1: Respondent incorporating "green" behaviors in daily life

\section{Green" for Many Means the Environment and Recycling:-}

By far, working for a better environment is the reason most often cited (58.6\%) to go "green". Women are significantly more likely than men to cite a better environment as a reason to be "green" $-64.9 \%$ versus $52.4 \%$, respectively. The desire for a cleaner environment may explain why recycling at home is the most common "green" activity that respondents make a part of their daily life - with $44.2 \%$ saying they do so. The survey does reveal a surprising finding - respondents 35 years or younger are significantly less likely than all other age segments to be active at-home recyclers. In fact, respondents 55 years or older are nearly twice as likely as respondents 18-24 years to say they are active at-home recyclers $-54.1 \%$ versus $28.7 \%$, respectively. 


\section{"Green" as a Lifestyle:-}

It is interesting to note that there is a marked difference in the motivation to go "green" between aspirationally "green" respondents and those who identify themselves as " $100 \%$ green". Aspirationally "green" respondents clearly point to working for a better environment (61.3\%) as the reason for incorporating "green" behaviors into their daily lives whereas, only $38.1 \%$ of " $100 \%$ green" respondents point to this cause. Among respondents who are " $100 \%$ green" no one reason for being "green" clearly stands out. Rather many reasons cluster together to paint a portrait of a segment for which being "green" is not solely defined by personal actions such as recycling, but rather identifies their lifestyle. The top reason cited by the " $100 \%$ green" segment included: to live a better quality of life $(36.6 \%)$, good for the community (35.4\%), desire to make a difference $(32.9 \%)$, and to set an example for others to follow $(31.5 \%)$.

\section{The Greening of the Internet:-}

The Internet is cited by more than one-third (39.4\%) of respondents as the best source of information on "green" products and practices. It is followed by television (18.4\%), friends and family (9.2\%), newspapers (7.1\%), magazines (6.5\%), and books (4.6\%). Among all age segments the Internet is considered the best source of "green" information followed by television - even among respondents 55 years and older. (Chart 2)

The most sought after online "green" content is healthy recipes $(34.8 \%)$; followed by information on recycling (30.7\%), alternative energy (27.6\%), simple living (26.5\%), and nature/outdoor living (26.5\%). One of the more interesting findings from the study is the difference in what is the most popular "green" information sought by men and women.

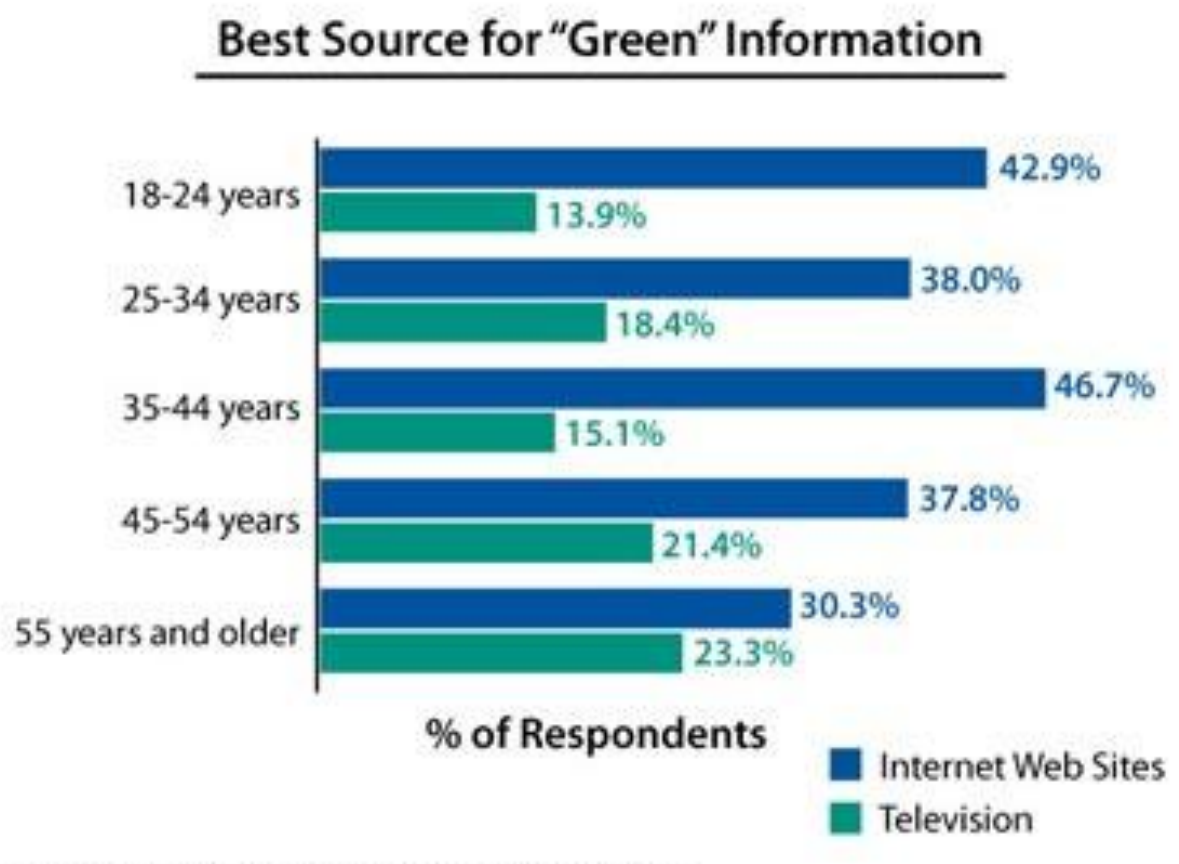

\section{Chart 2: Best source of "qreen" information}

\section{Consumers Recall “Green” Advertising Claims - But Skeptical:-}

A broad majority (81.7\%) of respondents notice claims made in advertisements that promote a company or a product as "green" or environmentally friendly. Over one-half (56.7\%) believe "green" claims made in advertisements; however few (4.7\%) "always" believe claims and one-half (52.0\%) are skeptical at times of them. One out of ten $(10.0 \%)$ say they never believe "green" claims made in an advertisement by a company or a product. Two-thirds $(67.5 \%)$ of aspirationally "green" respondents believe "green" claims in advertising, compared to $58.2 \%$ of " $100 \%$ green" respondents, and $32.3 \%$ of respondents who are not "green" at all.

Interestingly, $15 \%$ of respondents find "green" claims to be confusing or misleading. Men and women respond similarly; however, there are noted differences among age segments. 
Among the youngest age segments, $10 \%$ of 18-24 years and 25-34 years find "green" advertising claims to be confusing or misleading. This number increases to $17 \%$ among the 35-44 years and 45-54 years age segments, and continues to rise to fully one-fifth $(20.2 \%)$ of respondents 55 years or older

\section{Perception of Green Claims in Advertising}

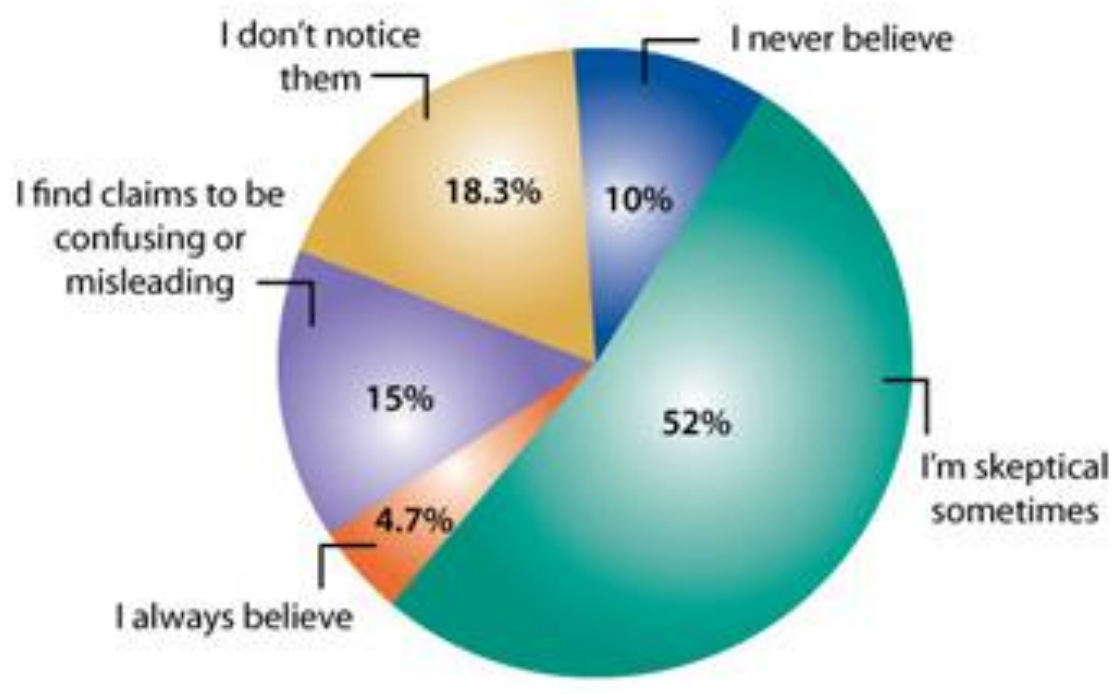

Chart 3: Perception of green advertising claims

\section{Consumers Will Pay a Premium for "Green" Products:-}

Overall consumers are willing to pay a premium for products they know are made out of "green"/ environmentally friendly or organic materials. The willingness to pay a premium, not surprisingly, is strongest among aspirationally "green" and 100\% "green" consumers. Among the aspirationally "green" segment, food and household products hold the most interest - with consumers exhibiting a willingness to pay a premium for a number of product categories they know to be "green" including: produce (66.6\%); juices and other bottled drinks (61.1\%); household cleaners (59.2\%); laundry detergents (58.7\%); and packaged food (58.2\%). Among the 100\% "green" segment there is significanant willingness - over $80 \%$ - to pay a premium for all product categories. This willingness includes all food categories, as well as garden/landscaping supplies (84.4\%), home improvement supplies $(84.0 \%)$, bedding $(83.3 \%)$, and health and beauty products $(82.0 \%)$.

\section{References:-}

1. Alston, K. and Roberts, J. P. (2005), "Partners in New Product Development: SC Johnson and the Alliance for Environmental Innovation," Corporate Environmental Strategy 6, no. 2: 111-28.

2. Bonti-Ankomah S.and E.K. Yiridoe, (2006), "Organic and conventional food: A literature review of the economics of consumers' perceptions and preference," Final Report. Organic Agriculture Centre of Canada. Nova Scotia Agricultural College, truro, Nova Scotia, Canada.

3. Brown, Joesph D. and Wahlers, Russell G. (1998), "The Environmentally Concerned Consumer: an Exploratory Study," Journal of Marketing Theory and Practice, Vol. 6, no. 2, pp. 39-47.

4. Buchholz, Rogene, A. (1998), "Principles of Environmental Management: The Greening of Business", $2^{\text {nd }}$ Ed., Upper Saddle River (N.J.): Prentice Hall.

5. Chan, Ricky, Y.K., and Lau, Lorett, B.Y. (2000), “Antecedents of green purchases: a survey in China," Journal of Consumer Marketing, Vol. 17, no. 4, pp. 338-357.

6. Christopher, Martin and McDonald, Malcolm (1995), Marketing, Sydney: Parkes.

7. Fuller, Donald A. (1999), Sustainable Marketing: Managerial-Ecological Issues, London, Sage Publications. 
8. Henriques, Irene and Sadorsky, Perry (1990), "The Relationship Between Environmental Commitment and Managerial Perceptions of Stakeholder Importance," Academy of Management Journal, Vol. 42, no. 1, pp. 8799.

9. Kimery, Kthryn M. and Rinehart, Shelley M. (1998), "Markets and Constituencies: An Alternative View of the Marketing Concept," Journal of Marketing Management, Vol. 14, no. 6, pp. 513-532.

10. Kotchen, Matthew J. (2006), "Green Markets and Private Provisions of Public Goods," Journal of Political Economy, vol. 114(4), pp.834-846.

11. McIntyre, Faye S., Thomas, Jr., James L. and Gilbert, Faye W. (1999), "Consumer Segments and Perception of Retail Ethics," Journal of Marketing Theory and Practice, Vol. 7, no. 2, pp. 43-53.

12. Meyer, Harvey (1999), "When the Cause is Just", Journal of Business Strategy, vol. 20(6), pp.27-32

13. Millock, K., L.G. Hansen, M. Wier and L.M. Anderson., (2002), "Willingness to Pay for Organic products: A Comparison between Survey Data and Panel Data from Denmark" ,AKF Denmark.

14. Ottman, Jacquelyn (1998), "Green Marketing: Opportunity for Innovation", $2^{\text {nd }}$ Ed., Lincolnwood, IL: NTC Business Books.

15. Peattie, Ken (1999), "Trappings Versus Substance in the Greening of Marketing Planning", Journal of Strategic Marketing, 7, 131-148

16. Piasecki, Bruce W., Fletcher, K.A., and Mendelson, F.J. (1999), Environmental Management and Business Strategy: Leadership Skills for the $21^{\text {st }}$ Century, New York: John Wiley and Sons.

17. Schuwerk, Melody E. and Lefkof-Hagins, Roxane (1995), "Green or Non-Green? Does Type of Appeal Matter When Advertising a Green Product?” Journal of Advertising, Vol. 24, no. 2, pp. 45-54.

18. Straughan, Robert, D. and Roberts, James, A. (1999), "Environmental Segmentation Alternatives: a Look at Green Consumer Behaviour in the New Millenium," Journal of Consumer Marketing, Vol. 16, no. 6, pp. 558575.

19. Vlosky, Richard P., Ozanne, Lucie K. and Fontenot, Renee J. (1999), "A conceptual model of US consumer willingness-to-pay for environmentally certified wood products," Journal of Consumer Marketing, Vol. 16, no. 2, pp. 122-136. 